\title{
An Initial Sustained Inflation Improves the Respiratory and Cardiovascular Transition at Birth in Preterm Lambs
}

\author{
KRISTINA S. SOBOTKA, STUART B. HOOPER, BETH J. ALLISON, ARJAN B. TE PAS, PETER G. DAVIS, COLIN J. MORLEY, \\ AND TIMOTHY J. M. MOSS

\begin{abstract}
The Ritchie Centre [K.S.S., S.B.H., B.J.A., T.J.M.M.], Department of Obstetrics and Gynaecology [S.B.H., T.J.M.M.], Monash University, Victoria 3168, Australia; Department of Pediatrics [A.B.P.], Leiden University Medical Centre, Leiden 2333 ZA, The Netherlands;
\end{abstract} \\ Neonatal Research [P.G.D., C.J.M.], Royal Women's Hospital, Melbourne, Victoria 3052, Australia
}

\begin{abstract}
A sustained inflation (SI) facilitates lung aeration after birth but may impair the neonatal cardiovascular transition. We aimed to determine the effect of an initial SI on pulmonary arterial and carotid blood flow (PBF and $\mathrm{CBF}$ ) after preterm birth. Fetal sheep were instrumented at $\sim 122 \mathrm{~d}$ of gestation (d). Lambs were delivered at $\sim 127 \mathrm{~d}$ and received either an initial SI $\left(40 \mathrm{~cm} \mathrm{H}_{2} \mathrm{O}\right.$ for $1 \mathrm{~min}$ or until a volume of $20 \mathrm{~mL} / \mathrm{kg}$ was administered) followed by ventilation for $30 \mathrm{~min}$ (SI; $n=7$ ) or ventilation for $30 \mathrm{~min}$ (non-SI; $n=6)$. At $10 \mathrm{~min}$ after ventilation onset, inspired $\mathrm{O}_{2}$ content increased from 21 to $100 \%$ for $10 \mathrm{~min}$. PBF, CBF, pulmonary arterial and carotid pressures, tidal volume, and inspiratory pressures were recorded. PBF was greater during the SI $(p<0.05)$ but thereafter was similar between groups. Non-SI lambs were hypoxemic and had higher CBF than SI lambs $(p<0.05)$. Cerebral oxygen delivery was constant in SI lambs but increased $\sim 4$-fold in non-SI lambs during ventilation with $100 \% \mathrm{O}_{2}(p<0.05)$. Lung compliance and respiratory status were better in SI than non-SI lambs $(p<0.05)$. A SI improved lung function without adverse circulatory effects, seemed to stabilize neonatal cerebral $\mathrm{O}_{2}$ delivery, and may protect against cerebral hyperoxia. (Pediatr Res 70: 56-60, 2011)
\end{abstract}

$\mathrm{I}_{\mathrm{s} u}^{\mathrm{n}}$ nfants born very preterm ( $<32 \mathrm{wk}$ of gestation) commonly suffer respiratory failure that requires intervention to initiate and sustain pulmonary gas exchange (1). However, it is unclear how this can be achieved without injuring the immature lung and impeding the physiological processes that underpin the transition to postnatal life (2). Before birth, the future airways of the lung are filled with liquid that must be cleared at birth to allow air entry and the onset of pulmonary gas exchange $(3,4)$. Recent imaging studies have demonstrated that airway liquid clearance is closely associated with inspiration and that transpulmonary pressures generated during inspiration play a major role $(3,5)$. The air/liquid interface moves distally with each inspiratory effort and as the liquid leaving the airways is replaced with inhaled air, not all of the inhaled air is exhaled during expiration $(3,5)$. Thus, there is a breath-by-breath increase in end-expiratory gas volumes leading to establishment of a functional residual capacity (FRC) (3). It is not surprising, therefore, that the application of a

Received November 29, 2010; accepted February 2, 2011

Correspondence: Stuart Hooper, Ph.D., The Ritchie Centre, Monash Institute of Medical Research, PO Box 5481, Clayton, VIC 3168, Australia; e-mail: stuart.hooper@monash.edu

Supported by the National Health and Medical Research Council (NHMRC) of Australia. sustained inflation (SI) pressure to overcome the long timeconstant required to move liquid through the airways into the distal air sacs can greatly facilitate airway liquid clearance $(6,7)$. However, it is currently unclear whether a sustained increase in intrathoracic pressure during the SI will adversely affect the cardiovascular transition at birth.

Before birth, pulmonary vascular resistance (PVR) is high, and the majority $(\sim 90 \%)$ of right ventricular output bypasses the lungs and flows from the pulmonary artery into the thoracic aorta (right-to-left shunting) via the ductus arteriosus. The onset of pulmonary ventilation after birth causes a large decrease in PVR, which greatly increases pulmonary blood flow (PBF), allowing it to accept the entire output from the right ventricle and a large contribution from the left ventricle via left-to-right shunting through the ductus arteriosus (i.e. from the systemic to pulmonary circulation); this contributes up to $50 \%$ of PBF immediately after birth (8). These cardiovascular changes at birth are central to the successful transition to postnatal life and are triggered by the reduction in PVR induced by lung aeration. However, it is well established that sustained increases in intrathoracic pressure increase PVR and decrease venous return leading to a decrease in cardiac output and cerebral vasodilation $(9,10)$. Thus, it is unclear whether an initial SI at the onset of pulmonary ventilation would impede the cardiovascular transition immediately after birth. The primary aim of this study was to determine whether an initial SI would impede the increase in PBF and adversely influence carotid blood flow (CBF) immediately after birth. A secondary aim was to compare the effects of a SI with shorter inflation times $(0.3 \mathrm{~s})$ on the respiratory transition at birth, particularly tidal volume $\left(V_{\mathrm{T}}\right)$ recruitment and lung compliance changes.

\section{METHODS}

All experimental procedures were approved by the relevant Monash University Animal Ethics Committee. Thirteen pregnant ewes underwent surgery at $122 \pm 2($ mean $\pm \mathrm{SD}$ ) days of gestation (d: term is $\sim 147 \mathrm{~d}$ ) for

\footnotetext{
Abbreviations: CA, carotid artery; $\mathbf{C B F}$, carotid blood flow; $\mathbf{F i O}_{2}$, fraction of inspired oxygen; FRC, functional residual capacity; LPA, left pulmonary artery; $\mathbf{P a C O}_{2}$, arterial partial pressure of carbon dioxide; $\mathbf{P a O} \mathbf{O}_{2}$, arterial partial pressure of oxygen; PBF, pulmonary blood flow; PEEP, positive end-expiratory pressure; PIP, peak inspiratory pressure; PVR, pulmonary vascular resistance; $\mathbf{S a O}_{2}$, arterial oxygenation saturation; $\mathbf{S I}$, sustained inflation; $\boldsymbol{V}_{\mathbf{T}}$, tidal volume
} 
insertion of catheters into a fetal carotid artery (CA) and jugular vein, the left pulmonary artery (LPA), and the amniotic sac. A 4-mm ultrasonic flow probe (Transonic Systems, Ithaca, NY) was placed around the LPA and the noncatheterized CA, as previously described (11). Fetal well-being was monitored daily after surgery by measuring fetal arterial partial pressure of oxygen $\left(\mathrm{PaO}_{2}\right)$, partial pressure of carbon dioxide $\left(\mathrm{PaCO}_{2}\right), \mathrm{pH}$, and arterial oxygen saturation $\left(\mathrm{SaO}_{2} ; \mathrm{ABL} 30\right.$, Radiometer, Copenhagen, Denmark).

At $127 \pm 4 \mathrm{~d}$ (mean $\pm \mathrm{SD}$ ), the ewe and fetus were anesthetized, and the fetal head and neck were exposed via cesarean section. The fetal trachea was intubated with a cuffed endotracheal tube $(3.5 \mathrm{~mm})$, and lung liquid was drained passively. A transcutaneous oximeter (Masimo, Irvine, CA) was attached around the right forelimb before the umbilical cord was clamped and cut. Lambs were delivered, dried, weighed, and placed under a radiant heater. Lambs received 5\% dextrose (i.v.) and were sedated (alfaxane i.v.: 5-15 $\mathrm{mg} / \mathrm{kg} / \mathrm{h}$; Jurox, East Tamaki, Auckland, New Zealand) to minimize spontaneous breathing during the experiment. Ewes were humanely killed (sodium pentobarbitone: $\sim 100 \mathrm{mg} / \mathrm{kg}$ i.v.) after delivery of the lamb.

Left pulmonary and carotid arterial blood flows [PBF and CBF, respectively] were recorded continuously (Powerlab; ADInstruments, Castle Hill, NSW, Australia), along with pressures in the LPA and CA (DTX Plus Transducer; Becton Dickinson, Singapore) from before delivery until the end of the experiment. Lambs were randomly assigned to receive either an initial SI or conventional ventilation (non-SI). Lambs in the SI group $(n=7)$ received an initial SI for either $1 \mathrm{~min}$ or until $20 \mathrm{~mL} / \mathrm{kg}(15 \mathrm{~mL} / \mathrm{kg}$ FRC and $5 \mathrm{~mL} / \mathrm{kg} V_{\mathrm{T}}$ ) of air had entered the lungs. The SI was delivered using a Neopuff (Fisher \& Paykel Healthcare, Panmure, Auckland, New Zealand) set to deliver a peak inspiratory pressure (PIP) of $40 \mathrm{~cm} \mathrm{H}_{2} \mathrm{O}$ and positive end-expiratory pressure (PEEP) of $5 \mathrm{~cm} \mathrm{H}_{2} \mathrm{O}$. After the SI, lambs were connected to a mechanical ventilator (Babylog $8000+$ ventilator; Drager, Lubeck, Germany) and ventilated in volume guarantee mode $\left(V_{\mathrm{T}} 7 \mathrm{~mL} / \mathrm{kg}\right)$ for $30 \mathrm{~min}$ (PEEP, $5 \mathrm{~cm} \mathrm{H}_{2} \mathrm{O}$; inspiratory time, $0.3 \mathrm{~s}$; and expiratory time, $0.6 \mathrm{~s}$ ). Ventilation was the same for lambs in the control group (non-SI; $n=6$ ) but without the initial SI; the PIP was initially adjusted every $30 \mathrm{~s}$ (by a maximum of $5 \mathrm{~cm} \mathrm{H}_{2} \mathrm{O}$ ) to achieve the desired $V_{\mathrm{T}}$. We recorded the delivered $V_{\mathrm{T}}$ and PIP simultaneously with arterial blood flow and pressure data. Lung compliance was calculated (12) according to the formula:

\section{Compliance $\left(\mathrm{mL} / \mathrm{cm} \mathrm{H}_{2} \mathrm{O} / \mathrm{kg}\right)=\left(V_{\mathrm{T}} / \mathrm{kg}\right.$ body weight $) /(\mathrm{PIP}-\mathrm{PEEP})$}

Ten minutes after the SI or the onset of ventilation in control lambs, the fraction of inspired oxygen $\left(\mathrm{FiO}_{2}\right)$ increased from 21 to $100 \%$ for $10 \mathrm{~min}$ and then reduced to $21 \%$ for a further $10 \mathrm{~min}$. These manipulations were performed to investigate the effects of oxygenation on PBF and CBF. Arterial blood gases were measured every $5 \mathrm{~min}$. Thirty minutes after delivery, lambs were killed by anesthetic overdose (sodium pentobarbitone; $130 \mathrm{mg} / \mathrm{kg}$ i.v.).

Analytical methods. Mean PBF, CBF, LPA, and CA pressures were averaged over 20 -s epochs immediately before and after umbilical cord occlusion, and at 1, 2, 3, 4, 5, 10, 15, 20, 25, and $30 \mathrm{~min}$ after the onset of ventilation. In addition, to interrogate changes in these variables during the initial SI, average values over each $5 \mathrm{~s}$ were calculated during the first minute. $V_{\mathrm{T}}$ and PIP were averaged for these same epochs. At times corresponding to when arterial blood gases were measured, we calculated carotid arterial blood $\mathrm{O}_{2}$ content to estimate cerebral $\mathrm{O}_{2}$ delivery (13) according to the formula:

\section{$\mathrm{O}_{2}$ delivery $=$ blood $\mathrm{O}_{2}$ content $\times$ blood flow}

where blood $\mathrm{O}_{2}$ content $=\left(\mathrm{Hb}\right.$ concentration $\left.\times \mathrm{SaO}_{2} \times 1.36\right)+\left(\mathrm{PaO}_{2} \times 0.003\right)$

Statistical methods. Data were analyzed using two-way repeated measures ANOVA with group (SI versus non-SI) and time as factors. Post hoc comparisons between groups and time points were performed using the Holm-Sidak test. Data are presented as mean \pm SEM unless otherwise stated.

\section{RESULTS}

Fetal well-being before delivery, as indicated by fetal blood $\mathrm{pH}, \mathrm{PaCO}_{2}, \mathrm{PaO}_{2}$, and $\mathrm{SaO}_{2}$ values were not different between groups (Table 1). The mean duration ( $\pm \mathrm{SD}$ ) of the initial SI was $40.1 \pm 21.3 \mathrm{~s}$. The average $V_{\mathrm{T}}$ was initially below the targeted volume $(7 \mathrm{~mL} / \mathrm{kg})$ in both groups of lambs but tended to be higher in SI lambs during the first $5 \mathrm{~min}$ of tidal ventilation (data not shown). Although $V_{\mathrm{T}}$ were not significantly different between groups, the inspiratory pressures required to achieve these volumes were higher (by $\sim 9-15 \mathrm{~cm}$
Table 1. Fetal arterial $\mathrm{pH}, \mathrm{PaCO}_{2}, \mathrm{PaO}_{2}$, and $\mathrm{SaO}_{2}$ before delivery

\begin{tabular}{llc}
\hline & SI & No SI \\
\hline $\mathrm{pH}$ & $7.38 \pm 0.01$ & $7.37 \pm 0.03$ \\
$\mathrm{PaCO}_{2}(\mathrm{~mm} \mathrm{Hg})$ & $42.0 \pm 1.6$ & $45 \pm 7.6$ \\
$\mathrm{PaO}_{2}(\mathrm{~mm} \mathrm{Hg})$ & $21.0 \pm 1.7$ & $20.6 \pm 3.4$ \\
$\mathrm{SaO}_{2}(\%)$ & $61.9 \pm 5.3$ & $60.1 \pm 4.1$ \\
\hline
\end{tabular}

Data are mean \pm SEM. Values were not different between groups.
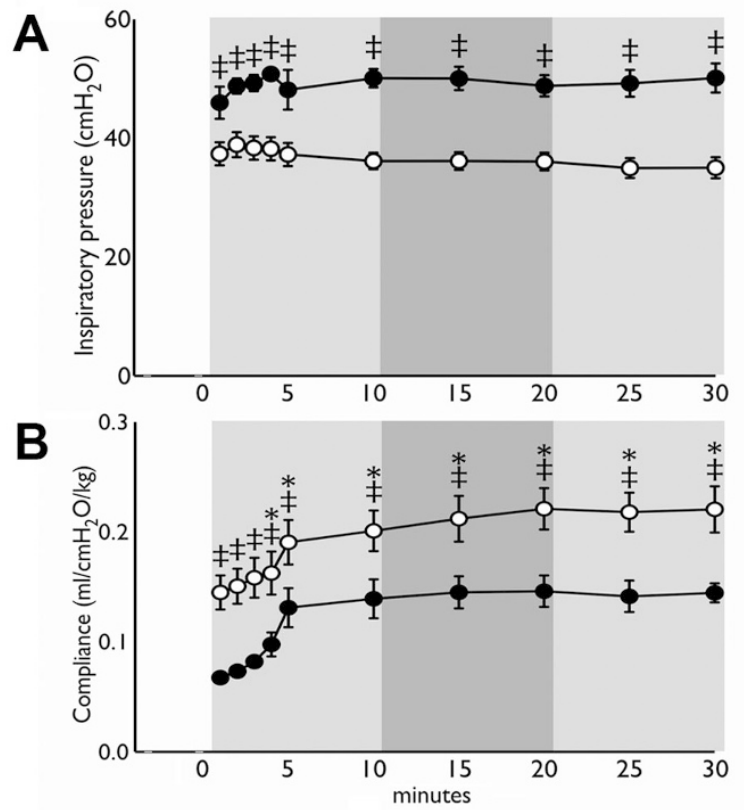

Figure 1. Inspiratory pressure $(A)$ and lung compliance $(B)$ in lambs receiving a SI $(\bigcirc)$ or no SI $(\bigcirc)$ with the initiation of ventilation (designated as time 0 ). Light shading indicates ventilation with air; dark shading indicates ventilation with $100 \% \mathrm{O}_{2}$. Data are mean \pm SEM. $\ddagger p<0.05$, SI $v$ s No SI; * $p<0.05$ ss "1 min" time point for both groups.

$\left.\mathrm{H}_{2} \mathrm{O}\right)$ in non-SI lambs compared with SI lambs $(p<0.001$; Fig. 1). As a result, lung compliance was greater in SI lambs compared with non-SI lambs throughout the 30-min ventilation period (Fig. 1).

The $\mathrm{PaCO}_{2}$ was significantly lower and $\mathrm{PaO}_{2}$ significantly higher ( $p<0.05$; Fig. 2$)$ in SI lambs compared with non-SI lambs during the entire experimental period, regardless of $\mathrm{FiO}_{2}$ (Fig. 2). In SI lambs, the $\mathrm{PaO}_{2}$ and $\mathrm{SaO}_{2}$ were both increased $(p<0.05)$ from fetal levels by ventilation with air and the $\mathrm{PaO}_{2}$ markedly increased further (to $210.2 \pm 44.4 \mathrm{~mm}$ $\mathrm{Hg}$ ) by ventilation with $100 \% \mathrm{O}_{2}$. Although the $\mathrm{SaO}_{2}$ increased in the SI group to $100 \%$ with the increase in $\mathrm{FiO}_{2}$, this was not statistically significant as the $\mathrm{SaO}_{2}$ levels were already high $(88.5 \pm 5.3 \%)$ during the previous ventilation in air. In contrast, we found it very difficult to maintain oxygen levels in non-SI lambs using conventional ventilation in air, despite having an almost identical $V_{\mathrm{T}}$ to that used in SI lambs. During ventilation in air, both the $\mathrm{PaO}_{2}$ and $\mathrm{SaO}_{2}$ in non-SI lambs were significantly reduced from fetal levels (Fig. 2) and were only increased in response to ventilation with $100 \% \mathrm{O}_{2}$. Ventilation with $100 \% \mathrm{O}_{2}$ increased the $\mathrm{PaO}_{2}$ and $\mathrm{SaO}_{2}$ from $11.0 \pm 0.1 \mathrm{~mm} \mathrm{Hg}$ and $16.0 \pm 1.5 \%$ to $58.1 \pm 9.9 \mathrm{~mm} \mathrm{Hg}$ and $89.5 \pm 6.1 \%$, respectively, within $10 \mathrm{~min}$ (Fig. 2). Returning the ventilation of non-SI lambs to air rapidly (within $5 \mathrm{~min}$ ) 

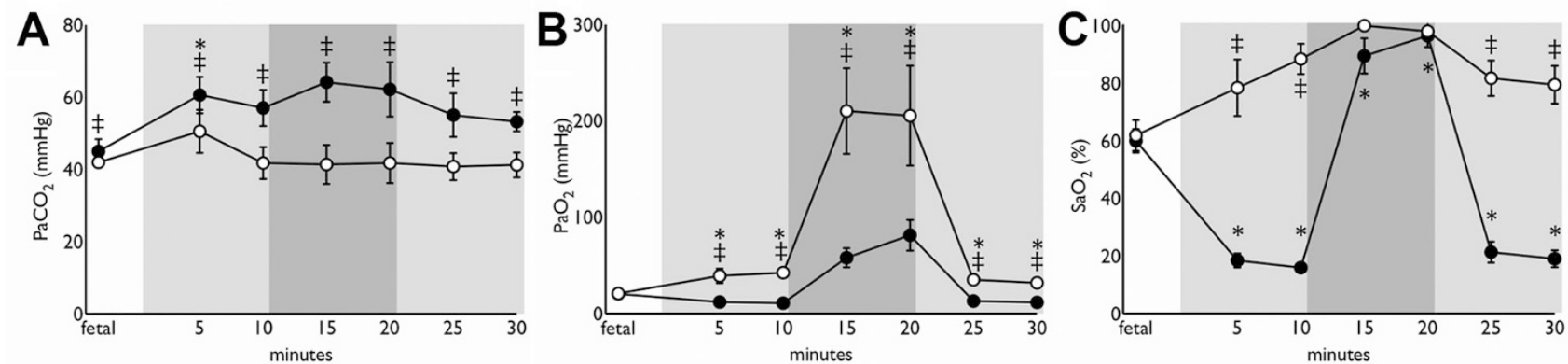

Figure 2. $\mathrm{PaCO}_{2}(A), \mathrm{PaO}_{2}(B)$, and $\mathrm{SaO}_{2}(C)$ in lambs receiving a $\mathrm{SI}(\bigcirc)$ or no $\mathrm{SI}(-)$ measured before umbilical cord occlusion (fetal) and after ventilation onset (designated as time 0). Light shading indicates ventilation with air; dark shading indicates ventilation with $100 \% \mathrm{O}_{2}$. Data are mean $\pm \mathrm{SEM}$. $\ddagger p<0.05$, SI $v s$ No SI; *p $<0.05 v s$ "fetal" time point for both groups.


Figure 3. Left pulmonary arterial blood flow $(A)$, pulmonary arterial pressure $(B)$, carotid arterial flow $(C)$, and carotid arterial pressure $(D)$ in lambs receiving a SI $(\bigcirc)$ or no SI $(\bullet)$ measured before (fetal) and after umbilical cord occlusion and after ventilation onset (designated as time 0). Light shading indicates ventilation with air; dark shading indicates ventilation with $100 \% \mathrm{O}_{2}$. Data are mean \pm SEM. $\ddagger p<0.05$, SI $v s$ No SI. $* p<0.05 v s$ "fetal" time point for both groups. $\dagger p<0.05 v s$ "fetal" time point for No SI group. $\$ p<0.05 v s$ "fetal" time point for SI group. reduced both the $\mathrm{PaO}_{2}$ and $\mathrm{SaO}_{2}(p<0.05)$ to values measured before the increase in $\mathrm{FiO}_{2}$ (Fig. 2).

At $20 \mathrm{~s}$ to $3 \mathrm{~min}$ after ventilation onset, PBF in SI lambs increased above fetal levels $(p<0.05)$ and was significantly greater than in non-SI lambs. In non-SI lambs, PBF did not increase above fetal levels until 2 min after ventilation onset $(p<0.05)$. Throughout the remainder of the experiment, PBF was similar in both groups. Pulmonary arterial pressure was transiently increased from fetal levels after umbilical cord occlusion in both groups ( $p<0.05$; Fig. 3). Pulmonary arterial pressure was not different between groups at any time point. Compared with values before ventilation, pulmonary arterial pressure was lower from $15 \mathrm{~min}$ in the SI group and from 20 min in the non-SI group.

In SI lambs, CBF tended to increase transiently with the onset of ventilation and then decreased over time (Fig. 3). In contrast, in non-SI lambs, CBF was significantly $(p<0.05)$ increased with ventilation onset over the first $5 \mathrm{~min}$ and remained elevated compared with SI lambs throughout the remainder of the experimental period ( $p<0.05$; Fig. 3). Carotid arterial pressure was higher in SI lambs compared with non-SI lambs $(p<0.05)$ from $15 \mathrm{~s}$ to $1 \mathrm{~min}$ after ventilation onset (i.e. during the SI period; Fig. 3). At 25 and

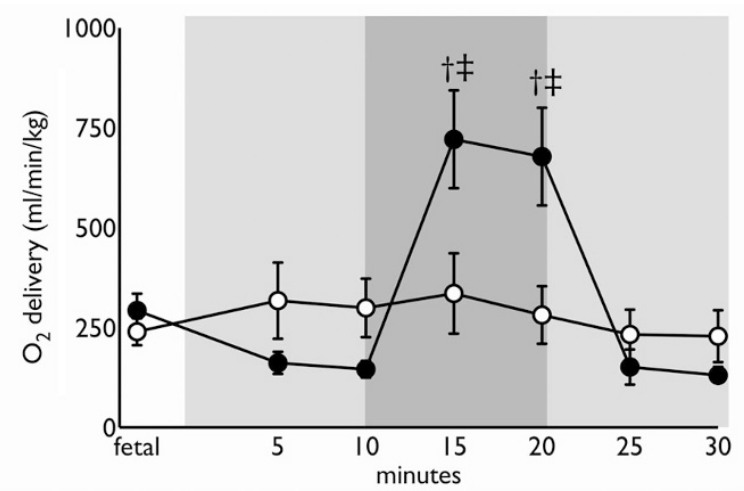

Figure 4. Carotid arterial oxygen delivery in lambs receiving a SI (O) or no SI (O) measured before umbilical cord occlusion (fetal) and after ventilation onset (designated as time 0). Light shading indicates ventilation with air; dark shading indicates ventilation with $100 \% \mathrm{O}_{2}$. Data are mean \pm SEM. $\ddagger p<$ 0.05 , SI vs No SI; $\dagger p<0.05$ vs "fetal" time point for No SI group.

30 min after ventilation onset, carotid arterial pressure was lower in non-SI lambs than SI lambs $(p<0.05)$.

In $\mathrm{SI}$ lambs, cerebral $\mathrm{O}_{2}$ delivery did not vary significantly through the experimental period (Fig. 4). In contrast, cerebral $\mathrm{O}_{2}$ delivery in non-SI lambs tended to decrease, relative to fetal levels, during ventilation with air (Fig. 4) and was 
markedly increased, $\sim 4$-fold ( $p<0.05$ ), in response to ventilation with $100 \% \mathrm{O}_{2}$. Cerebral $\mathrm{O}_{2}$ delivery was $\sim 2$-fold higher $(p<0.05)$ in non-SI lambs than in the SI group during ventilation with $100 \% \mathrm{O}_{2}$. The resumption of ventilation with air lowered cerebral $\mathrm{O}_{2}$ delivery to levels seen before ventilation with $100 \% \mathrm{O}_{2}$ in non-SI lambs but had no effect in SI lambs.

\section{DISCUSSION}

This study has demonstrated that an initial SI markedly improved both the cardiovascular and respiratory transition at birth in lambs delivered preterm. Our primary aim was to demonstrate that the cardiovascular transition was not impeded by an initial sustained increase in intrathoracic pressure. We found that PBF was higher in SI lambs compared with non-SI lambs during the SI and remained similar to that measured in non-SI lambs throughout the remainder of the experimental period. CBF tended to decrease in SI lambs after ventilation and was markedly lower than that measured in non-SI lambs. A postventilation decrease in CBF is a welldescribed feature of well-oxygenated newborns and reflects an oxygen-mediated decrease in cerebral blood flow (14). In addition, despite having similar $V_{\mathrm{T}}$, the peak inflation pressures required to achieve these volumes in SI lambs were significantly less than those required in non-SI lambs. As a result, a SI significantly increased lung compliance for at least the first $30 \mathrm{~min}$ after ventilation onset. Combined with the very large differences in blood oxygenation and $\mathrm{PaCO}_{2}$ levels, these data indicate that a SI markedly improved and did not impede the physiological transition to newborn life.

Previous studies have demonstrated that an initial SI facilitates uniform lung aeration and FRC recruitment in preterm rabbits $(6,7)$ and, in combination with subsequent nasal CPAP, reduces the need for intubation and the risk of moderate to severe bronchopulmonary dysplasia in preterm human infants (15). As lung aeration at birth involves the movement of liquid through the airways $(5,16)$, the high resistance to liquid movement (compared with air) must increase the time required for the liquid to move distally into the gas exchange regions $(3,4)$. Logically, therefore, a SI provides the time required for the relatively slow flowing liquid to move through the airways ahead of the initial entry of air. Furthermore, as the rate of liquid movement must vary across the lung depending on airway size, if the SI is of sufficient duration, most of the lung can be aerated by the initial inflation. This feature has been demonstrated clearly in imaging studies, which showed that an initial SI can fully recruit FRC and uniformly distribute gas within the lung during subsequent tidal ventilation $(6,7)$.

Initially, we found that $V_{\mathrm{T}}$ tended to be higher in lambs following a SI, but we were targeting a set $V_{\mathrm{T}}$ so it is not surprising that these differences were not significant and diminished with time. However, the PIP required to achieve these volumes were markedly higher in non-SI lambs indicating that SI lambs had lungs that were significantly more compliant. In view of previous imaging studies $(6,7)$, we consider that this resulted from a much greater degree of lung aeration in SI lambs, which is consistent with the markedly higher $\mathrm{PaO}_{2}$ and lower $\mathrm{PaCO}_{2}$ levels in these SI lambs. Indeed, we found it very difficult to ventilate non-SI lambs in air and were not able to achieve adequate oxygenation without increasing the $\mathrm{FiO}_{2}$, despite a high mean PBF in these lambs (see below). Thus, it is likely that only small parts of the lung were successfully aerated in non-SI lambs. As a result, because we were delivering a set $V_{\mathrm{T}}(7 \mathrm{~mL} / \mathrm{kg})$, a gas volume that was appropriate for the entire lung was likely delivered to a small portion of the lung, probably causing overdistension and injury in those regions.

In non-SI lambs, increasing $\mathrm{FiO}_{2}$ to 1.0 markedly improved blood oxygenation but had no effect on ventilation parameters (e.g. lung compliance), $\mathrm{PaCO}_{2}$, or $\mathrm{PBF}$. As such, the increase in oxygenation must have been achieved by simply increasing the partial pressure gradient for oxygen diffusion across the air/blood barrier. Other potential contributors, such as improved lung aeration, increased pulmonary perfusion, or an increase in ventilation/perfusion matching, would have led to physiological changes such as an increase in lung compliance, an increase in PBF, and a decrease in $\mathrm{PaCO}_{2}$ levels. Thus, in terms of respiratory function, increasing the $\mathrm{FiO}_{2}$ had little physiological benefit other than increasing blood oxygenation levels, which in this context may be of dubious benefit (see below). Increasing $\mathrm{FiO}_{2}$ to 1.0 in $\mathrm{SI}$ lambs, however, did not significantly alter most cardiorespiratory parameters examined. As these lambs had mean $\mathrm{SaO}_{2}$ of $88.5 \pm 5.3 \%$ during the preceding period of ventilation in air, increasing the $\mathrm{FiO}_{2}$ to 1.0 simply increased the $\mathrm{SaO}_{2}$ to $100 \%$, which was not a statistically significant increase.

The results of this study indicate clearly that a SI does not impede the pulmonary transition at birth, particularly the increase in PBF. Indeed, we found that during the SI, PBF was higher in SI lambs than non-SI lambs, which was surprising considering the sustained increase in intrathoracic pressure. However, as venous return is reduced by $\sim 50 \%$ immediately before ventilation onset, because of the occlusion of the umbilical cord (8), it is possible that any further reduction caused by a sustained increase in thoracic pressure is insignificant in comparison. Aeration of the lungs underlies the increase in PBF after birth, so the increased PBF in the SI group is presumably the consequence of more uniform lung aeration. As the non-SI lambs were very hypoxic and it is likely that their lungs were not completely aerated, we are surprised that the PBF response to ventilation onset was not reduced in these lambs. This suggests that these lambs had a large ventilation/perfusion mismatch, compared with SI lambs, which is consistent with the finding of severe hypoxemia and hypercapnia despite a large increase in PBF and normal minute ventilation. Furthermore, our results demonstrate that oxygenation status of the newborn had little or no overall effect on PBF.

Numerous previous studies have demonstrated that, after birth, CBF gradually decreases, which is considered to be an autoregulatory process in response to an increase in oxygenation $(14,17,18)$. This response was observed in SI lambs, with CBF gradually decreasing from $40.2 \pm 7.8 \mathrm{~mL} / \mathrm{min} / \mathrm{kg}$ at $1 \mathrm{~min}$ after birth to $19.9 \pm 4.3 \mathrm{~mL} / \mathrm{min} / \mathrm{kg}$ by the end of the experiment. However, in non-SI lambs, CBF remained ele- 
vated and, although it tended to decrease during ventilation with $100 \% \mathrm{O}_{2}$, it was significantly greater than in SI lambs. It is highly likely that the elevated CBF in non-SI lambs is an autoregulatory response to the substantial hypoxemia these lambs were suffering, with the goal of sustaining oxygen delivery to the brain $\left(\mathrm{O}_{2}\right.$ delivery is a product of blood flow and $\mathrm{O}_{2}$ content). Indeed, although oxygen delivery tended to decrease and be lower in non-SI lambs than in SI lambs during ventilation in air, these differences were not significant.

An interesting consequence of the higher CBF in non-SI lambs was that a rapid increase in oxygenation caused by increasing the $\mathrm{FiO}_{2}$ dramatically increased cerebral oxygen delivery in these lambs. Although the consequences of such a large and rapid increase in cerebral oxygen delivery are unknown, the potential to cause hyperoxia-induced brain injury, particularly in the presence of significant acidaemia, is high. In contrast, an increase in $\mathrm{FiO}_{2}$ in $\mathrm{SI}$ lambs did not affect cerebral oxygen delivery because the arterial blood was already highly saturated with oxygen before the $\mathrm{FiO}_{2}$ increased. Thus, the small increase in $\mathrm{O}_{2}$ content could be accounted for by a small decrease in CBF. It is important to recognize that we did not directly measure CBF or oxygen delivery in this study. Although measurements of carotid flow provide a valid $(19,20)$ and commonly used $(21,22)$ means of measuring relative changes in total brain blood flow, it provides no information on regional blood flow or oxygenation. The use of near-infrared spectroscopy to directly measure CBF and oxygenation or microspheres to assess regional blood flow would provide more detailed information on the changes in cerebral hemodynamics and tissue oxygenation. These data have important implications for the resuscitation of human neonates. They emphasize the dangers that are inherent in rapidly increasing the inspired $\mathrm{FiO}_{2}$ in response to clinical signs of cyanosis or low saturation measurements as indicated by pulse oximetry. Clinicians need to be cognizant of the physiological adaptations that have occurred in response to hypoxemia in the first minutes of life before instituting changes in treatment, such as rapidly alternating the inspired $\mathrm{O}_{2}$ content.

In summary, the findings of this study clearly demonstrate that a SI does not impede the PBF increase and markedly improves the respiratory adaptation to the onset of pulmonary ventilation after birth. The improvement in respiratory function in SI lambs was likely due to a much greater degree of lung aeration with fewer regions with airway liquid retention. Improved aeration increases lung compliance (7) and enhances the lung's gas exchange potential by increasing the surface area available for gas exchange and improving ventilation/perfusion matching. Furthermore, our studies demonstrate that physiological adaptations, such as an increase in $\mathrm{CBF}$, can minimize the effect of hypoxemia on cerebral oxygen delivery immediately after birth. Thus, simply increasing the $\mathrm{FiO}_{2}$ to correct hypoxemia can potentially have injurious effects on the brain caused by hyperoxia. The improved oxygenation we observed after an initial SI suggests that adopting such a strategy might reduce the need for such interventions in human neonates and may also provide protection against neonatal brain injury.

Acknowledgments. We thank Ms. Karyn Rodgers for her assistance with these experiments.

\section{REFERENCES}

1. Clark RH, Gerstmann DR, Jobe AH, Moffitt ST, Slutsky AS, Yoder BA 2001 Lung injury in neonates: causes, strategies for prevention, and long-term consequences. J Pediatr 139:478-486

2. Jobe AH, Ikegami M 1998 Mechanisms initiating lung injury in the preterm. Early Hum Dev 53:81-94

3. Siew ML, Te Pas AB, Wallace MJ, Kitchen MJ, Lewis RA, Fouras A, Morley CJ, Davis PG, Yagi N, Uesugi K, Hooper SB 2009 Positive end-expiratory pressure enhances development of a functional residual capacity in preterm rabbits ventilated from birth. J Appl Physiol 106:1487-1493

4. te Pas AB, Davis PG, Hooper SB, Morley CJ 2008 From liquid to air: breathing after birth. J Pediatr 152:607-611

5. Hooper SB, Kitchen MJ, Wallace MJ, Yagi N, Uesugi K, Morgan MJ, Hall C, Siu KK, Williams IM, Siew M, Irvine SC, Pavlov K, Lewis RA 2007 Imaging lung aeration and lung liquid clearance at birth. FASEB J 21:3329-3337

6. te Pas AB, Siew M, Wallace MJ, Kitchen MJ, Fouras A, Lewis RA, Yagi N, Uesugi K, Donath S, Davis PG, Morley CJ, Hooper SB 2009 Effect of sustained inflation length on establishing functional residual capacity at birth in ventilated premature rabbits. Pediatr Res 66:295-300

7. te Pas AB, Siew M, Wallace MJ, Kitchen MJ, Fouras A, Lewis RA, Yagi N, Uesugi K, Donath S, Davis PG, Morley CJ, Hooper SB 2009 Establishing functional residual capacity at birth: the effect of sustained inflation and positive end-expiratory pressure in a preterm rabbit model. Pediatr Res 65:537-541

8. Crossley KJ, Allison BJ, Polglase GR, Morley CJ, Davis PG, Hooper SB 2009 Dynamic changes in the direction of blood flow through the ductus arteriosus at birth. J Physiol 587:4695-4704

9. Meredith KS, deLemos RA, Coalson JJ, King RJ, Gerstmann DR, Kumar R, Kuehl TJ, Winter DC, Taylor A, Clark RH, Null DM 1989 Role of lung injury in the pathogenesis of hyaline membrane disease in premature baboons. J Appl Physiol 66:2150-2158

10. Fessler HE, Brower RG, Wise RA, Permutt S 1991 Effects of positive end-expiratory pressure on the gradient for venous return. Am Rev Respir Dis 143:19-24

11. Polglase GR, Wallace MJ, Grant DA, Hooper SB 2004 Influence of fetal breathing movements on pulmonary hemodynamics in fetal sheep. Pediatr Res 56:932-938

12. Moss TJ, Newnham JP, Willett KE, Kramer BW, Jobe AH, Ikegami M 2002 Early gestational intra-amniotic endotoxin: lung function, surfactant, and morphometry. Am J Respir Crit Care Med 165:805-811

13. Lister G, Walter TK, Versmold HT, Dallman PR, Rudolph AM 1979 Oxygen delivery in lambs: cardiovascular and hematologic development. Am J Physiol 237:H668-H675

14. Connors G, Hunse C, Gagnon R, Richardson B, Han V, Rosenberg H 1992 Perinatal assessment of cerebral flow velocity wave forms in the human fetus and neonate. Pediatr Res 31:649-652

15. te Pas AB, Walther FJ 2007 A randomized, controlled trial of delivery-room respiratory management in very preterm infants. Pediatrics 120:322-329

16. Siew ML, Wallace MJ, Kitchen MJ, Lewis RA, Fouras A, Te Pas AB, Yagi N, Uesugi K, Siu KK, Hooper SB 2009 Inspiration regulates the rate and temporal pattern of lung liquid clearance and lung aeration at birth. J Appl Physiol 106:18881895

17. Camp D, Kotagal UR, Kleinman LI 1982 Preservation of cerebral autoregulation in the unanesthetized hypoxemic newborn dog. Brain Res 241:207-213

18. Jones MD Jr, Traystman RJ, Simmons MA, Molteni RA 1981 Effects of changes in arterial O2 content on cerebral blood flow in the lamb. Am J Physiol 240:H209$\mathrm{H} 215$

19. Covert RF, Schreiber MD, Torgerson LJ, Torgerson RW, Miletich DJ 1996 Prediction of cerebral blood flow in fetal lambs by carotid artery ultrasonic flow transducer. Reprod Fertil Dev 8:157-162

20. van Bel F, Roman C, Klautz RJ, Teitel DF, Rudolph AM 1994 Relationship between brain blood flow and carotid arterial flow in the sheep fetus. Pediatr Res 35:329-333

21. Miller SL, Chai M, Loose J, Castillo-Melendez M, Walker DW, Jenkin G, Wallace EM 2007 The effects of maternal betamethasone administration on the intrauterine growth-restricted fetus. Endocrinology 148:1288-1295

22. Bennet L, Peebles DM, Edwards AD, Rios A, Hanson MA 1998 The cerebral hemodynamic response to asphyxia and hypoxia in the near-term fetal sheep as measured by near infrared spectroscopy. Pediatr Res 44:951-957 